\title{
Comparison of clinical and epidemiological character- istics of pelvic inflammatory disease classified by endocervical cultures of Neisseria gonorrhoeae and Chlamydia trachomatis
}

Address for reprints: Dr F N Judson, Disease Control Service, 605 Bannock Street, Denver, Colorado 80204-4507, USA

Accepted for publication 15 November 1985 limited basis in 1981. Since 1981 we have obtained endocervical specimens for cultures for $C$ trachomatis from all women suspected of having PID.

In our experience, women who present to STD clinics with abdominal pain tend to have rather mild pelvic symptoms and signs, and the diagnosis of salpingitis is often unreliable. ${ }^{1}$ Verification by laparoscopy is seldom possible or practical. The availability of endocervical chlamydial cultures does not resolve this dilemma, but it does provide the opportunity to classify and contrast further women with a clinical diagnosis of PID based on culture results. In the study published here we compared the clinical and epidemiological characteristics of PID in women seen at the Denver Metro Health Clinic whose endocervical cultures were positive for Neisseria gonorrhoeae only, $C$ trachomatis only, both organisms, or neither organism. 


\section{Patients and methods}

The Denver Metro Health Clinic provides diagnostic and treatment services for STD on request to residents of the Denver metropolitan area. Services are available seven hours each weekday and are free and confidential. The clinic records about 23000 patient visits a year and diagnoses and treats more than $60 \%$ of cases of gonorrhoea reported from the city and county of Denver. The population of the clinic is about $60 \%$ white, $20 \%$ black, and $17 \%$ hispanic. Other ethnic groups comprise less than $3 \%$. A standardised form was used to collect extensive data for each woman making an initial visit to the clinic.

We conducted a retrospective chart review of all women diagnosed as having PID at the Denver Metro Health Clinic during a two year period from 1 January 1982 to 31 December 1983. PID was defined as: (1) abdominal pain in association with at least one reproductive tract sign including tenderness on cervical movement, adnexal tenderness, or an adnexal mass; or (2) two or more reproductive tract signs. All women suspected of having PID had two endocervical specimens taken for the culture for $\boldsymbol{N}$ gonorrhoeae, which were processed as described previously. ${ }^{1}$ In addition, two endocervical specimens for the culture of $C$ trachomatis were obtained using sterile, cotton tipped applicators (Abco, Milwaukee, Wisconsin, USA. The specimens were inoculated into $3.7 \mathrm{ml}(1$ dram) vials containing glass beads and $1 \mathrm{ml}$ of $2 \mathrm{SP}$ transport medium $(0.2 \mathrm{ml} / 1$ sucrose, $0.02 \mathrm{ml} / 1$ phosphate, $25 \mathrm{mg} / 1$ nystatin, $10 \mathrm{mg} / 1$ gentamicin; M A Bioproducts, Walkersville, Maryland, USA) and immediately refrigerated. If specimens could not be inoculated into cells within 24 hours they were stored at $-70^{\circ} \mathrm{C}$, then rapidly thawed and inoculated when cells became available. Specimens were vortexed to break up cells and enhance suspensions, and $0.2 \mathrm{ml}$ aliquots were inoculated into each of three $3.7 \mathrm{ml}$ glass vials containing a $12 \mathrm{~mm}$ coverlip coated with a confluent layer of $\mathrm{McC}$ oy cells (M A Bioproducts). Vials were centrifuged at $3000 \times \mathrm{g}$ for one hour at 25$35^{\circ} \mathrm{C}$, the inoculum discarded, and the monolayer rinsed once with Eagle's minimum essential medium containing $10 \%$ fetal calf serum, $5.4 \mathrm{mg} / 1$ dextrose, 20 $\mathrm{mmol} / \mathrm{l} \mathrm{HEPES}, 0.21 \mathrm{mg} / 1$ sodium bicarbonate, $10 \mathrm{mg} / 1$ gentamicin, and $0.5 \mathrm{mg} / 1$ cyclohexamide (M A Bioproducts). After the monolayers had been rinsed $1 \mathrm{ml}$ of medium was added to each vial and the cultures incubated at $35^{\circ} \mathrm{C}$. After being incubated for 48 hours monolayers from two vials were stained with iodine. The monolayer from the third vial was stained after 72 hours. Coverslips were examined under a microscope at $60 \mathrm{x}$ and $40 \mathrm{x}$ magnifications, and chlamydial inclusions were counted.

Patients were divided into four groups based on culture results: those yielding $N$ gonorrhoeae only, yielding $C$ trachomatis only, yielding both organisms, or yielding neither organism. Clinical and epidemiological characteristics that were compared included: age; race; sexual contact with men with gonorrhoea or non-gonococcal urethritis; history and description of vaginal discharge, dysuria, or abdominal pain; number of days since last sexual contact and number of different contacts in the previous 30 days; contraceptive history; number of pregnancies; recent menstrual history; history of STDs; use of antibiotics in the previous 30 days; results of endocervical cultures; and results of a complete pelvic examination.

Statistical analysis used Yate's correction of the $\chi^{2}$ test, and the normal deviate test.

\section{Results}

Of the 89 women clinically diagnosed as having PID, $N$ gonorrhoeae only was isolated from the cervix of 24 (27\%), $C$ trachomatis only from $16(18 \%)$, both organisms from $14(16 \%)$, and neither organism from 35 (39\%). Table I compares the epidemiological characteristics of these four groups of women. Age and recent sexual history were similar in each group. More black than white or hispanic women yielded positive endocervical cultures for $N$ gonorrhoeae $(\mathrm{p}<0.005)$. More women yielding chlamydiae only or both organisms than women in the other two groups had had recent sexual contact with a partner with gonorrhoea $(p<0.005)$. More women yielding neither organism than in the other three groups reported previous gonococcal infection, though this difference was not significant. No significant differences were seen between groups regarding exposure to a partner with non-gonococcal urethritis, history of trichomoniasis, parity, use of antibiotics, or contraceptive methods used. Furthermore, table II shows that no significant differences were found between groups regarding duration of abdominal pain, relation of pain to phases of the menstrual cycle, abdominal rebound tenderness, or reproductive tract signs. More women yielding $N$ gonorrhoeae than in the other three groups had purulent endocervical discharge $(p<0.05)$. Only one of 84 women tested had a temperature higher than $38 \mathrm{C}$.

\section{Discussion}

Though the rates of gonococcal PID seem to be declining in some populations, rates of chlamydial PID may be increasing. ${ }^{4}$ Recent reports have implicated C trachomatis as the causative agent in as many as 20$60 \%$ of patients. ${ }^{56}$ Whereas gonococcal PID is seen commonly in highly symptomatic women presenting to emergency rooms or gynecological inpatient services, chlamydial disease has been characterised as having a relatively mild and protracted course, and has a greater 
TABLE I Comparison of epidemiological characteristics of 89 women with pelvic inflammatory disease (PID), classified by endocervical culture results for Neisseria gonorrhoeae $(\mathrm{Ng})$ and Chlamydia trachomatis (Ct), attending Denver Metro Health Clinic, 1982-3. Figures are numbers (\%) of women unless shown otherwise.

\begin{tabular}{|c|c|c|c|c|}
\hline Epidemiological characteristics & $\begin{array}{l}\mathrm{Ng} \text { positive } \\
\mathrm{Ct} \text { negative } \\
(n=24)\end{array}$ & $\begin{array}{l}\mathrm{Ng} \text { negative } \\
\mathrm{Ct} \text { positive } \\
(n=16)\end{array}$ & $\begin{array}{l}\mathrm{Ng} \text { negative } \\
\mathrm{Ct} \text { positive } \\
(n=14)\end{array}$ & $\begin{array}{l}\mathrm{Ng} \text { negative } \\
\mathrm{Ct} \text { negative } \\
(n=35)\end{array}$ \\
\hline Median (range) age (years) & $25(19-42)$ & $21(16-29)$ & $24(19-44)$ & $24(16-45)$ \\
\hline $\begin{array}{l}\text { Race: } \\
\text { Black } \\
\text { White } \\
\text { Hispanic }\end{array}$ & $\begin{array}{r}10(41 \cdot 7) \\
11(45 \cdot 8) \\
3(12 \cdot 5)\end{array}$ & $\begin{array}{l}6(37 \cdot 5) \\
7(43 \cdot 8) \\
3(18 \cdot 8)\end{array}$ & $\begin{array}{l}4(28 \cdot 6) \\
6(42 \cdot 9) \\
4(28 \cdot 6)\end{array}$ & $\begin{array}{r}8(22 \cdot 9) \\
21(60 \cdot 0) \\
6(17 \cdot 1)\end{array}$ \\
\hline Mean (range) days since last sexual contact & $4(1-80)$ & $4(1-14)$ & $6(1-30)$ & $4(1-30)$ \\
\hline Mean (range) No of sexual contacts in previous 30 days & $1(0-3)$ & $1(1-2)$ & $1(1-2)$ & $1(1-180)$ \\
\hline Contact of gonorrhoea & $8(33 \cdot 3)$ & $0(0.0)$ & $4(28 \cdot 6)$ & $2(5 \cdot 7)$ \\
\hline Contact of non-gonococcal urethritis & $1(4 \cdot 2)$ & $2(12 \cdot 5)$ & $1(7 \cdot 1)$ & $3(8 \cdot 6)$ \\
\hline History of gonorrhoea & $9(37 \cdot 5)$ & $6(37 \cdot 5)$ & $5(35 \cdot 7)$ & $22(62 \cdot 9)$ \\
\hline History of trichomoniasis & $7(29 \cdot 2)$ & $4(25 \cdot 0)$ & $5(35 \cdot 7)$ & $12(34 \cdot 3)$ \\
\hline History of pregnancy & $20(83 \cdot 3)$ & $12(75 \cdot 0)$ & $11(78 \cdot 6)$ & $27(77 \cdot 1)$ \\
\hline Use of antibiotics within 30 days & $4(16 \cdot 7)$ & $1(6 \cdot 3)$ & $0(0.0)$ & $4(11 \cdot 4)$ \\
\hline $\begin{array}{l}\text { Contraceptive use: } \\
\text { Pill } \\
\text { Intrauterine device } \\
\text { Other } \\
\text { None }\end{array}$ & $\begin{array}{r}4(16 \cdot 7) \\
3(12 \cdot 5) \\
5(20 \cdot 8) \\
12(50 \cdot 0)\end{array}$ & $\begin{array}{l}4(25 \cdot 0) \\
1 \quad(6 \cdot 3) \\
2(12 \cdot 5) \\
9(56 \cdot 3)\end{array}$ & $\begin{array}{l}2(14.3) \\
0(0 \cdot 0) \\
3(21 \cdot 4) \\
9(64 \cdot 3)\end{array}$ & $\begin{array}{r}6(17 \cdot 1) \\
4(11 \cdot 4) \\
10(28 \cdot 6) \\
15(42 \cdot 9)\end{array}$ \\
\hline
\end{tabular}

TABLE II Comparison of clinical symptoms and signs in 89 women with pelvic inflammatory disease (PID), classified by endocervical culture results for Neisseria gonorrhoeae $(\mathrm{Ng})$ and Chlamydia trachomatis (Ct), attending Denver Metro Health Clinic, 1982-3. Figures are numbers (\%) of women.

\begin{tabular}{|c|c|c|c|c|}
\hline Clinical symptom or sign & $\begin{array}{l}\mathrm{Ng} \text { positive } \\
\mathrm{Ct} \text { negative } \\
(n=24)\end{array}$ & $\begin{array}{l}\mathrm{Ng} \text { negative } \\
\mathrm{Ct} \text { positive } \\
(n=16)\end{array}$ & $\begin{array}{l}\mathrm{Ng} \text { positive } \\
\text { Ct positive } \\
(n=14)\end{array}$ & $\begin{array}{l}\mathrm{Ng} \text { negative } \\
\mathrm{Ct} \text { negative } \\
(n=35)\end{array}$ \\
\hline $\begin{array}{l}\text { Duration of abdominal pain* (da } \\
\quad \leq 14 \\
>14\end{array}$ & $\begin{array}{r}18(75 \cdot 0) \\
5(20 \cdot 8)\end{array}$ & $\begin{array}{r}14(87 \cdot 5) \\
1(6 \cdot 3)\end{array}$ & $\begin{array}{rr}14 & (100.0) \\
0 & (0.0)\end{array}$ & $\begin{array}{r}27(77 \cdot 1) \\
4(11 \cdot 4)\end{array}$ \\
\hline $\begin{array}{l}\text { Day of menstrual cycle pain beg } \\
\begin{array}{l}0-7 \\
8-14 \\
15-21 \\
22-31 \\
\text { Before last menstrual period }\end{array}\end{array}$ & $\begin{array}{l}5(20 \cdot 8) \\
5(20 \cdot 8) \\
3(12 \cdot 5) \\
1 \quad(4 \cdot 2) \\
9(37 \cdot 5)\end{array}$ & $\begin{array}{l}1(6 \cdot 3) \\
5(31 \cdot 3) \\
0(0 \cdot 0) \\
2(12 \cdot 5) \\
7(43 \cdot 8)\end{array}$ & $\begin{array}{ll}3 & (21 \cdot 4) \\
3 & (21 \cdot 4) \\
2 & (14 \cdot 3) \\
3 & (21 \cdot 4) \\
3 & (21 \cdot 4)\end{array}$ & $\begin{array}{r}5(14 \cdot 3) \\
8(22 \cdot 9) \\
3(8 \cdot 6) \\
3(8 \cdot 6) \\
12(34 \cdot 3)\end{array}$ \\
\hline $\begin{array}{l}\text { Abdominal rebound tenderness } \\
\text { Cervical motion tenderness } \\
\text { Adnexal tenderness } \\
\text { Adnexal mass }\end{array}$ & $\begin{array}{r}4(16 \cdot 7) \\
15(62 \cdot 5) \\
20(83 \cdot 3) \\
3(12 \cdot 5)\end{array}$ & $\begin{array}{r}3(18 \cdot 8) \\
10(62 \cdot 5) \\
14(87 \cdot 5) \\
1(6 \cdot 3)\end{array}$ & $\begin{array}{rr}4 & (28 \cdot 6) \\
10 & (71 \cdot 4) \\
9 & (64 \cdot 3) \\
0 & (0 \cdot 0)\end{array}$ & $\begin{array}{r}7(20 \cdot 0) \\
16(45 \cdot 7) \\
32(91 \cdot 4) \\
2(5 \cdot 7)\end{array}$ \\
\hline $\begin{array}{l}\text { Vaginal discharge: } \\
\text { None/normal/menses } \\
\text { Excessive white } \\
\text { Purulent vaginal } \\
\text { Purulent endocervical }\end{array}$ & $\begin{array}{l}8(33 \cdot 3) \\
8(33 \cdot 3) \\
1(4 \cdot 2) \\
7(29 \cdot 2)\end{array}$ & $\begin{array}{l}5(31 \cdot 3) \\
6(39 \cdot 5) \\
2(12 \cdot 5) \\
3(18 \cdot 7)\end{array}$ & $\begin{array}{ll}5 & (35 \cdot 7) \\
3 & (21 \cdot 4) \\
2 & (14 \cdot 3) \\
4 & (28 \cdot 6)\end{array}$ & $\begin{array}{r}12(34 \cdot 3) \\
17(48 \cdot 6) \\
4(11 \cdot 4) \\
2(5 \cdot 7)\end{array}$ \\
\hline
\end{tabular}

*Not all women experienced abdominal pain and numbers in each category may therefore not total " $n$ ". 
incidence of serious long term medical sequelae. As most women with PID who seek treatment present to outpatient clinics, where sophisticated diagnostic and culture techniques may not be available, we thought it worthwhile to evaluate the clinical presentation of PID in women attending our STD clinic, who were classified according to endocervical culture results for $N$ gonorrhoeae and $C$ trachomatis.

Of 89 women identified as having PID, $38(42 \cdot 7 \%)$ yielded $N$ gonorrhoeae from the endocervix and $30(33.7 \%)$ yielded $C$ trachomatis. These data compare well with published reports from Scandinavia where endocervical cultures were positive for $N$ gonorrhoeae in $10-30 \%$ and for $C$ trachomatis in $20-60 \%$ of patients with acute salpingitis ${ }^{56}$ and with American reports of $10-70 \%$ of patients yielding $N$ gonorrhoeae from the cervix and over $20 \%$ yielding $C$ trachomatis. ${ }^{79}$ In general, studies from the United States of America have shown higher rates of gonococcal and lower rates of chlamydial PID than those from Sweden, Finland, and Norway. Differences in patient populations, isolation techniques, and severity of cases, however, make direct comparisons impossible. We know of no reports that have evaluated specifically the relationof these organisms to the clinical and epidemiological characteristics of women outpatients with suspected PID.

In our clinic the proportion of all patients with PID associated with gonorrhoea has declined from $61.4 \%$ in $1978 / 9$ to $42 \cdot 7 \%$ in $1982 / 3$, which paralleled a decrease in the overall prevalence of gonorrhoea in women attending the clinic from $19 \%$ to $11.4 \%$. At the same time the proportion of non-gonococcal PID has risen from $38 \%$ to $57 \cdot 3 \%$. these trends have been observed in other populations $s^{4}$ and have been attributed to improved efforts to treat and control gonorrhoea in the absence of similar efforts to treat and control non-gonococcal urethritis and other chlamydial infections. We were unable to lend support to this hypothesis because both the prevalence and incidence of non-gonococcal urethritis in men attending our clinic actually declined appreciably between $1978 / 9$ and $1982 / 3^{10}$ and because we found no appreciable association between a history of sexual contact with men with non-gonococcal urethritis and a diagnosis of either non-gonococcal or chlamydial PID. Our data probably failed to document the expected associations because most women are unaware that they have been exposed to a man with non-gonococcal urethritis, less than $50 \%$ of non-gonococcal urethritis is caused by $C$ trachomatis, few endocervical chlamydial infections result in PID, and the clinical diagnosis of PID is not accurate.

We identified several clinical and epidemiological findings that generally agreed with prior studies. Women with gonococcal PID were more likely to be black, to have a recent history of sexual contact with a partner with gonorrhoea, and to have a purulent endocervical discharge, ${ }^{11} 12$ and women with non-gonococcal PID were more likely to report a history of gonococcal infection ${ }^{11}$. In contrast with previous studies, and perhaps because of the small numbers in each of our groups, we found no significant differences between groups regarding other clinical signs and symptoms. In particular, we did not find an association between PID and other well established risk factors such as nulliparity and the use of intrauterine devices. ${ }^{1113}$ Neither could we confirm the reported protective effect of oral contraceptives against gonococcal PID ${ }^{11}{ }^{14}$ or an increase in incidence of infection with $C$ trachomatis in users of oral contraceptives. ${ }^{15}$

The difficulty in accurately diagnosing PID without laparoscopy probably further compromised our ability to assess the associations of certain clinical and epidemiological risk factors with endocervical culture results. Serological testing for antibodies against $C$ trachomatis might have made these relations clearer, but as with laparoscopy these techniques are not routinely used. Moreover, Ripa and colleagues recently found that measuring chlamydial antibodies in serum was inconclusive in diagnosing current infection. ${ }^{16}$ Similar serological testing for gonococcal infection has also been unrewarding.

The study published here documented a strong association between $C$ trachomatis and PID in an STD clinic, but also underlined the unreliability of a clinical diagnosis of PID based on mild or equivocal pelvic findings. Many traditional features of PID that have been well described in studies of inpatients are not found in outpatients. As three quarters of all PID is seen in outpatient clinics, however, and as untreated PID can result in chronic pelvic pain, infertility rates of $30 \%$ or more, and up to a tenfold increased in ectopic pregnancy, ${ }^{14} 17$ the need for better understanding of this disease is obvious. The role of $C$ trachomatis as an aetiological agent is especially important because the organism often produces a mild and indolent infection that is very difficult to diagnose, even though sequelae are similar to those associated with gonococcal PID.

A lack of specificity argues against the use of endocervical cultures for either $N$ gonorrhoeae or $C$ trachomatis in selecting treatment for a patient suspected of having PID. These organisms often occur together and additional aetiological agents must be considered. Established clinical and epidemiological characteristics of women with PID are not reliable. As recommended by the Centers for Disease Control, ${ }^{18}$ optimum treatment should always include antimicrobials with proved efficacy against both $N$ gonorrhoeae and $C$ trachomatis. Mucopurulent cervicitis, recently described by Brunham et al as the ignored counterpart in women of urethritis in men, ${ }^{19}$ should also be recognised and treated appropriately to prevent the 
development of PID. Finally, agressive efforts should be made to identify and treat epidemiologically sexual partners of women suspected of having PID.

It may not be possible to generalise results from the present study to other outpatient populations where the prevalence of $C$ trachomatis and othe STDs may be lower and risk factors may be different. Additional larger studies are needed to clarify further the clinical presentation and optimum management of women presenting to outpatients clinics with PID.

We thank Josephine Ehret for performing chlamydial cultures, the staff of the Denver Metro Health Clinic for collecting data, Katie Andersen and Karen Martinez for secretarial help, and the Division of Sexually Transmitted Diseases, Centers for Disease Control, Atlanta, Georgia, for funding support for chlamydial cultures.

\section{References}

1. Tavelli BG, Judson FN. Comparison of the clinical and epidemiologic characteristics of gonococcal and nongonococcal pelvic inflammatory disease as seen in a clinic for sexually transmitted diseases, 1978 and 1979.Sex Transm Dis (in press).

2. Mărdh P-A, Ripa T, Svensson L, Westrom L. Chlamydia trachomatis infection in patients with acute salpingitis. N EnglJ Med 1977;296:1377-9.

3. Judson FN. Epidemiology and control of nongonococcal urethritis and genital chlamydial infections: a review. Sex Transm Dis 1981;8:117-26.

4. Forslin L, Falk V, Danielsson D. Changes in the incidence of acute gonococcal and nongonococcal salpingitis: five-year study from an urban area of central Sweden. British Journal of Venereal Diseases 1978;54:247-50.

5. Paavonen J, Saikku P, Vesterinen E, Aho K. Chlamydia trachomatis in acute salpingitis. British Journal of Venereal Diseases 1979;55:203-6.

6. Treharne JD, Ripa KT, Mårdh P-A, Svensson L, Westrom L, Darougar S. Antibodies to Chlamydia trachomatis in acute salpingitis. British Journal of Venereal Diseases 1979;55:26-9.

7. Holmes KK, Eschenbach DA, Knapp JS. Salpingitis: overview of etiology and epidemiology. Am J Obstet Gynecol 1980;138: 893-900.

8. O'Hare PA, Fiumara NJ, McCormack WM. Pelvic inflammatory disease among women presenting to emergency rooms of hospitals in Massachusetts. Am J Obstet Gynecol 1980;138: 909-12.

9. Sweet RL, Draper DL, Schachter J, James J, Hadley WK, Brooks GF. Microbiology and pathogenesis of acute salpingitis as determined by laparoscopy: what is the appropriate site to sample? Am J Obstet Gynecol 1980;138:985-9.

10. Judson FN. Assessing the number of genital chlamydial infections in the United States. J Reprod Med 1985;30:269-72.

11. Eschenbach DA, Harnisch JP, Holmes KK. Pathogenesis of acute pelvic inflammatory disease: role of contraception and other risk factors. Am J Obstet Gynecol 1977;128:838-50.

12. Jacobsen $L$, Westrom $L$. Objectivized diagnosis of acute pelvic inflammatory disease. Am J Obstet Gynecol 1969;105:1088-98.

13. Senanayake $P$, Kramer DG. Contraception and the etiology of pelvic inflammatory disease: new perspectives. Am $\mathrm{J}$ Obstet Gynecol 1980;138:852-60.

14. Westrom L. Incidence, prevalence, and trends of acute pelvic inflammatory disease and its consequences in industrialized countries. Am J Obstet Gynecol 1980;138:880-92.

15. Shafer MA, Beck A, Blain B, et al. Chlamydia trachomatis: important relationships to race, contraception, lower genital tract infection, and Papanicolaou smear. J Pediatr 1984;104: 141-6.

16. Ripa KT, Lowhagen G-B, Johannisson G. Chlamydia-specific cervical and serum antibodies in female STD clinic patients. European Journal of Sexually Transmitted Diseases 1984; 1:177-80.

17. Cates W Jr. Sexually transmitted organisms and infertility: the proof of the pudding. Sex Transm Dis 1984;11:113-6.

18. Anonymous. Sexually transmitted diseases treatment guidelines - 1982. MMWR 1982;31(supp 1):32-60.

19. Brunham RC, Paavonen J, Stevens LE, et al. Mucopurulent cervicitis - the ignored counterpart in women of urethritis in men. N Engl J Med 1984;311:1-6. 